NASA

Technical Memorandum 104394

$1 N-3 \%$

38700

pr 19 Avscom

Technical Report 90-C-014

\title{
Spur-Gear Optimization Using SPUROPT Computer Program
}

Harold H. Coe

Lewis Research Center

Cleveland, Ohio

(NASA-TM-104394) SPUR-GEAR OPTIMIZATION USING SPUROPI COMPUTLR PROGRAM (NASA) $19 \mathrm{p}$

$N 91-31648$ CSCL $13 I$ 


\title{
SPUR GEAR OPTIMIZATION USING SPUROPT COMPUTER PROGRAM
}

\author{
Harold H. Coe \\ National Aeronautics and Space Administration \\ Lewis Research Center \\ Cleveland, Ohio 44135
}

\begin{abstract}
SUMMARY
SPUROPT, a computer program developed for optimizing spur gear designs, was updated by installing a new subroutine that uses AGMA 908-B89 standards to calculate the J-factor for determining tooth-bending stress. The updated SPUROPT program was then used to optimize a spur gear set for either maximum fatigue life, minimum dynamic load, or minimum weight. All calculations were made with constraints on as many as 13 parameters by using three design variables: the number of teeth, diametral pitch, and tooth-face width. Results depended largely on constraint values. When the limiting bending stress was set at a high value, the optimal solution was the highest allowable number of teeth. When the allowable bending stress was lowered, the optimal solution moved toward the fewest number of teeth permitted. Final results were also affected by the amount of transmission error. A lower error permitted a higher number of teeth.
\end{abstract}

\section{INTRODUCTION}

Gears are an important component of many power transmission systems. Their design can greatly influence durability, reliability, and maintainability of a system, as well as its overall weight. As a result, it is becoming increasingly important to develop the best gear design for a given situation, as system design criteria become increasingly stringent. One technique for providing reliable design methodology is to use numerical optimization methods along with an analytical gear code. A study by Vanderplaats resulted in a spur gear design computer program called SPUROPT. This program, fully described in reference 1, combined spur gear analysis routines with the COPES/ADS optimization program (ref. 2). In reference 1 the example problem for maximizing surface fatigue life indicated an improvement of almost 200 percent for the optimized gear design over the original design. This was a single calculation, however. For a more complete evaluation of SPUROPT, the program needed to be exercised over a range of variables. This report evaluates the results of running the computer program SPUROPT over a range of variables.

\section{PROGRAM SPUROPT}

SPUROPT, described more fully in reference 1, is composed of two parts. One part consists of analytical routines that calculate such properties as tooth-bending stress, surface stress, dynamic loading, scoring criteria, flash temperature, weight, and fatigue life. The second part contains the COPES/ADS optimizing routines (refs. 1 and 2). This part of the program seeks to determine the proper combination of values of the design variables (such as number of teeth and face width) that results in maximization (or minimization) of an objective function (e.g., fatigue life) while other properties such as tooth-bending stress or gear weight are subject to constraints. For further discussions about numerical optimization and the structure of the SPUROPT program, see reference 1. 
The example problem in reference 1 maximized the fatigue life of a set of spur gears for specific material and lubrication constants, and for a given operating condition (load, speed, or temperature), by constraining design variables such as number of teeth, module (diametral pitch), and tooth-face width. The program was subject to limitations on bending stress, Hertz or contact stress, flash temperature, contact ratio, center distance, gear weight, and tooth-widthto-diameter ratio. This example problem was the starting point for all computer runs described in this paper.

\section{RESULTS AND DISCUSSION}

Initially, we ran the original SPUROPT program for the same spur gear life-maximization problem as given in reference 1 . Typical gear input data are shown in table I, and a sample input data set is shown in table II. A complete explanation of required input data is given in references 1 and 2 . The program requires engineering units for input values and provides output values in engineering units. All SI values shown in this report were obtained by conversion. During these initial runs, some parameters were changed (e.g., shaft diameter and bending-stress limits) to determine the effects of these variables. Then, the program was updated by substituting a different routine for the $\mathrm{J}$-factor calculation and was run again for evaluation. This activity is discussed in the following sections.

\section{Initial Runs}

The results of the initial runs showed that gear fatigue life for the final optimal values of the design variables increased over that life obtained with the original design. In watching the optimization process, we observed interesting intermediate results from SPUROPT. Figure 1 shows the values of the design variables, as controlled by the optimizer, and values of the objective function (gear fatigue life) for each trial calculation during solution of the life-maximization problem. After the 30 th trial, there is a large change in the number of teeth (fig. 1(a)) as well as a steady improvement in fatigue life (fig. 1(d)).

Summary results for a typical run are given in table III, which also includes results for the initial design values (table I) as well as bounds placed on the problem. A study of the output data shows very small values for the tooth-bending stress for some trials. This low bending stress was caused by some unusual values for the J-factor. Figure 2 shows values of the J-factor as calculated by the program for each trial. A comparison of figure 2 with figure 1(a) shows that the unusual values occurred with the higher numbers of teeth. Note that the J-factor should always be positive and less than 1 .

J-factor calculation in SPUROPT was based on a model presented in reference 3. Similar unusual values of the J-factor have been noted previously (Errichello, R., 1989, Geartech, Albany, CA, letter to Dennis Townsend, NASA Lewis Research Center) for an equivalent set of equations. To obtain better J-factor values, we decided to replace the subroutine GEOF AC (ref. 1), which was used to calculate the J-factor, with equations shown in AGMA 908-B89 (ref. 4). Thus, a new subroutine called JFACTR was written and installed. Subsequent calculations were made using this new subroutine. 


\section{J-Factor Calculations Using AGMA 908-B89}

Several assumptions were made so that the equations shown in AGMA 908-B89 could be used successfully with the optimizing routines. First, we decided to use a rack cutter. Therefore, the number of teeth on the cutter was set at 10000 . The cutter addendum was set at 1.4, and there was no offset for the cutter-tip radius. Second, the cutter-tip radius was calculated by using the equation from reference 3 , as shown in reference 1 .

Figure 3 shows values of the J-factor as calculated by the new subroutine for the same input conditions as in figure 2. This time, values remained less than 1 for all trials. (Note the scale change.)

\section{Final Runs}

The modified SPUROPT program was run again with the same input conditions as for figure 1 (table I), and the process plots of the design variables looked similar to those of the original run. Final optimal values for design variables, noted in table IV, were 60 teeth, 2.12 module (12.0 diametral pitch), and $7.1 \mathrm{~mm}$ (0.28 in.) face width; fatigue life was 1985 million revolutions.

Changing the shaft diameter from 203 to $51 \mathrm{~mm}$ (8.0 to $2.0 \mathrm{in}$.) did not change optimal values, although the tooth-bending stress was lowered slightly. However, when the program was run with the allowable bending stress lowered to $414 \mathrm{MPa}(60000 \mathrm{psi})$ and the module limit set at 4.23 (6.0 diametral pitch) to permit the lower limit on the number of teeth to be reached, optimal values of the design variables changed. The process plot looked somewhat different, as shown in figure 4. This time, the number of teeth was driven to the lower limit, and the optimal values - as indicated in table $\mathrm{V}$ - were 30 teeth, 4.23 module (6.0 diametral pitch), and $7.1 \mathrm{~mm}(0.28 \mathrm{in}$.) face width, with a fatigue life of 1564 million revolutions. Note that the face width is a result of the limit placed on face-width-to-diameter ratio, and that center distance and bending-stress values were also at their constraint limits.

Changing the input value of the measured error on the pair of mating teeth affected the final optimal values. A lower measured error resulted in a slightly higher number of teeth. Investigation of this effect led to the discovery of some small errors in the program; however, they tended to compensate for each other. After these errors were corrected, the program was run several more times with the same initial gear set - first with the same initial values, then with different bounds and different objective functions. Run 22 used the corrected program with the same input data that were used for table V; results are shown in table VI. A comparison of tables V and VI indicates that the program errors were minor, since final computed values were only slightly different.

Results for subsequent runs are given in table VII, which shows "standard" bounds for each variable, initial values for the problem, and resulting optimal values for design variables. For runs in which the problem was changed slightly, only the new, or changed, bounds are given. (All other bounds remained at standard values.) The program was run to solve three problems: fatigue-life maximization, dynamic-load minimization, and weight minimization. A special lifeoptimization run was also made. These runs are discussed in the following sections. 
Fatigue-life maximization. - Four runs with different bounds gave different optimal results. In table VII run 22 shows the optimal design parameters for the life problem with "standard" bounds. These limits (as well as the initial values) are the same as those for the sample problem in reference 1 , except that the bending stress is $414 \mathrm{MPa}$ (60000 psi) instead of $1241 \mathrm{MPa}$ (180 $000 \mathrm{psi})$ and the module, 4.23 (6.0 pitch) instead of 3.18 (8.0 pitch). Fatigue life increased from the initial 666 million revolutions to 1592 million revolutions. Constraints that were at their limiting value are bending stress, center distance, and face-width-to-diameter ratio. This run produced virtually the same design as noted previously - before the small corrections to the program - 31 teeth, 4.03 module $(6.3$ pitch $)$, and $7.1 \mathrm{~mm}(0.28 \mathrm{in}$.$) face width.$

In run 23 , the bounds on the width-to-diameter ratio were changed to allow the face width to reach the full limit of $10.2 \mathrm{~mm}(0.400 \mathrm{in}$.). This resulted in a fatigue life of 7096 million revolutions. Bending stress and center distance remained at their limiting values.

For run 25, the face-width ratio was raised to further observe the effect of this parameter, and actual face-width limits were changed to match. This change resulted in a very large increase in fatigue life, $154 \mathbf{4 7 5}$ million revolutions. For this optimization, constraints on weight, face-width ratio, and dimetral pitch were at their limits.

Finally, in run 26, the face-width ratio limit was increased to allow a face width of up to 50 percent of the gear diameter. Resulting optimal design variables were 49.2 teeth, 2.12 module (12 pitch), and a $30.7-\mathrm{mm}$ (1.21 in.) face width (ratio only 0.29 ); the fatigue life was over 200000 million revolutions. Constraints on weight and pitch were at their limits.

The program was then run for life maximization to determine the effect of using different input values for the measured error. Run 22 shows the results of using a typical error value of $0.025 \mathrm{~mm}(0.001 \mathrm{in}$.), as given in table I; run 20 used a smaller error of $0.012 \mathrm{~mm}(0.0005 \mathrm{in}$.), and run 21, a larger error of $0.05 \mathrm{~mm}(0.002 \mathrm{in}$.). The smaller error resulted in a higher number of teeth being optimal for the design (40, versus 31 with the typical error), with the same constraints at their limits and about the same fatigue life. With the larger error (run 21), however, the optimizer was unable to find a viable design - that is, a set of design variables that would satisfy all constraints. The bending stress could not be held to less than the upper limit, even with a low number of teeth (minimum diametral pitch), a maximum face-width ratio, and a maximum center distance. So, for run 24 , the allowable face-width ratio was changed to permit a full face width of $10.2 \mathrm{~mm}(0.400 \mathrm{in}$.). This resulted in a solution in which the number of teeth, module, center distance, and face width were all at their limiting values, whereas the bending stress was lowered slightly, to only 8 percent over limit.

To find a viable solution for the problem, changes were made to run 35 . The maximum face-width-to-diameter ratio was changed from 0.10 to 0.20 , and the maximum tooth width was raised to $63.5 \mathrm{~mm}(2.5 \mathrm{in}$.). This resulted in a solution with the width-to-diameter ratio, gear weight, and bending stress at their limiting values. Optimal design variables were 36.3 teeth, 3.26 module ( $7.8 \mathrm{pitch}$ ), and $23.7 \mathrm{~mm}(0.93 \mathrm{in}$.) face width, with a fatigue life of about 3000 million revolutions. Thus, with the higher measured error, wider teeth were required to keep the bending stress within limits while satisfying all other constraints.

Dynamic load minimization. - Using the same standard bounds as for the fatigue-life maximization studies, the SPUROPT program was run again to seek the optimal values of design variables with which to obtain a minimum dynamic load for the initial gear set of table I. Results are noted for run 27 , where the pitch and number of teeth were at minimum limits, and 
the bending stress and center distance were at maximum limits. These results are close to the optimal values determined for the life-maximization problem, a fact not really surprising, because of the relationship between load and gear life.

Weight minimization. - Again, with the same standard bounds as for previous studies, SPUROPT was used to find the optimum design values with which to obtain minimum weight for the initial gear set. Results given for run 28 show the number of teeth, the bending stress and the face-width ratio were at their limits. To determine if another solution with wider teeth existed, run 30 was made with a higher ratio limit. Such a solution was not found, however, and the minimum weight remained at $0.66 \mathrm{~kg}(1.45 \mathrm{lb})$. It is not surprising that these results are close to the dynamic load optimal values, since dynamic load is influenced by the effective masses of the pinion and gear blanks, as noted in reference 1.

Special life-optimization run. - A small modification, allowing transmitted power to remain constant for all designs during optimization, was made to the program, so that we could determine if optimal values would be affected. (All previous calculations assumed a constant force transmission across all designs.) For the initial gear set, the modification did not greatly influence final design. The optimal results for run 33 were virtually the same as for run 25 , with the same bounds. The $51.5 \mathrm{~kW}(69 \mathrm{hp})$ input for run 33 was the power associated with table I input data. Run 32 (table VII) shows the optimal results when the limit on the weight was raised to $4.54 \mathrm{~kg}(10.0 \mathrm{lb})$. In this run, the number of teeth, pitch, center distance, and weight were all at their maximum limits. Bending stress was under its limit, and fatigue life was essentially infinite (over $10000 \mathrm{yr}$ ).

\section{CONCLUDING REMARKS}

Even though the optimizing routines were able to produce viable designs and provide optimal values for design variables, these values should not be considered final solutions (i.e., not final design values). The analytical model is still somewhat simplified, so many designs can be checked. Each optimal solution will have to be examined more thoroughly for a given application.

The Modified Feasible Directions method, using polynominal interpolation with bounds for the one-dimensional search, was the optimization technique used for these runs; this is the default algorithm. Other choices were available in the program but were not used in this study.

Note also that since SPUROPT considers all variables to be continuous, often the optimal value for the number of teeth will not be a whole number. The nearest whole number could be chosen, however, and the program run again without using the optimizer to obtain final values for the calculated parameters.

\section{SUMMARY OF RESULTS}

Computer program SPUROPT was run for a set of spur gear conditions to determine an optimal design, and in this manner, evaluate the program. The original program was updated by installing a subroutine that calculated the J-factor based on AGMA 908-B89. With this change, the following results were obtained: 
1. The SPUROPT program produced viable designs (i.e., the objective function was maximized, or minimized, while other parameters were held within the bounds of stated constraints, unless such a solution was not possible).

2. Changing the shaft size from 203 to $51 \mathrm{~mm}$ ( 8.0 to $2.0 \mathrm{in}$.) did not affect final results.

3. Changing the transmission error from 0.025 to $0.013 \mathrm{~mm}(0.001$ to $0.005 \mathrm{in}$.) produced a design with a lower module (higher diametral pitch) and a higher number of teeth.

\section{REFERENCES}

1. Vanderplaats, G.N.; Chen, X.; and Zhang, N.-T.: Gear Optimization. NASA CR-4201, Dec. 1988.

2. Vanderplaats, G.N.: COPES/ADS - A Fortran Program for Engineering Synthesis Using the ADS Optimization Program. Version 2.0, Engineering Design Optimization, Inc., Santa Barbara, Ca, 1988.

3. Mitchiner, R.G.; and Mabie, H.H.: The Determination of the Lewis Form Factor and the AGMA Geometry Factor J for External Spur Gear Teeth. ASME Journal of Mechanical Design, Vol. 104, Jan. 1982, pp. 148-158.

4. AGMA 908-B89: Geometry Factors for Determining the Pitting Resistance and Bending Strength of Spur, Helical and Herringbone Gear Teeth. American Gear Manufacturers Association, Alexandria, VA. 
TABLE I. - TYPICAL GEAR INPUT DATA FOR INITIAL DESIGN GEAR AND PINION ${ }^{a}$

\begin{tabular}{|c|}
\hline Input parameter \\
\hline$\ldots \ldots \ldots \ldots \ldots \ldots \ldots \ldots$ \\
\hline Module, $\mathrm{mm}\left(\right.$ diametral pitch, in. $\left.{ }^{-1}\right) \ldots \ldots \ldots \ldots \ldots \ldots 3.18(8.00)$ \\
\hline 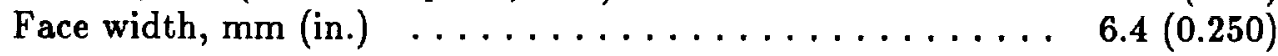 \\
\hline Pressure angle, $\operatorname{deg} \ldots \ldots \ldots \ldots \ldots \ldots \ldots \ldots \ldots \ldots \ldots$ \\
\hline Normal load, $N(\mathrm{lb}) \quad \ldots \ldots \ldots \ldots \ldots \ldots \ldots \ldots \ldots \ldots$ \\
\hline 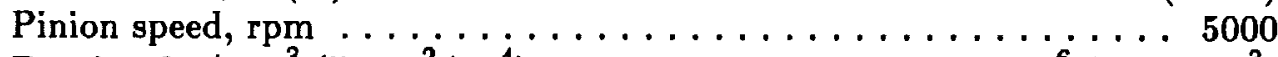 \\
\hline Density, $\mathrm{kg} / \mathrm{mm}^{3}\left(\mathrm{lb}-\mathrm{sec}^{2} /\right.$ in. $\left.^{4}\right)$ \\
\hline Young's modulus, $\left.\mathrm{GPa}(\mathrm{psi}) \quad \ldots \ldots \ldots \ldots \ldots \ldots \ldots \ldots \ldots \ldots+10^{6}\right)$ \\
\hline Poisson's ratio $\ldots \ldots \ldots \ldots \ldots \ldots \ldots \ldots \ldots \ldots \ldots \ldots \ldots \ldots$ \\
\hline Surface roughness, $\mu \mathrm{m} \quad \ldots \ldots$ \\
\hline Measured error, mm (in.) \\
\hline Shaft length, mm (in.) $\ldots \ldots \ldots \ldots \ldots \ldots \ldots \ldots \ldots$ (20.0) \\
\hline Shaft diameter, $m m$ (in.) $\ldots \ldots \ldots \ldots \ldots \ldots \ldots \ldots \ldots$. $\ldots \ldots \ldots$ (2.0) \\
\hline$\ldots \ldots \ldots \ldots \ldots \ldots \ldots \ldots$ \\
\hline$\ldots \ldots \ldots \ldots \ldots$ \\
\hline Hardness ratio $\ldots$. \\
\hline$\ldots \ldots \ldots \ldots \ldots \ldots$ \\
\hline Pressure-viscosity coefficient, $\mathrm{mm}^{2} / \mathrm{N}\left(\mathrm{in}^{2} / \mathrm{lb}\right) \ldots$ \\
\hline Viscosity at ambient temperature, $\mathrm{cP}\left(\mathrm{lb}-\mathrm{sec} / \mathrm{in}^{2}{ }^{2}\right) \ldots \ldots 124\left(0.18 \times 10^{-5}\right)$ \\
\hline Temperature-viscosity coefficient, $K\left({ }^{\circ} \mathrm{R}\right)$ \\
\hline Ambient temperature $\mathrm{K}\left({ }^{\circ} \mathrm{F}\right) \ldots \ldots \ldots \ldots \ldots \ldots \ldots \ldots \ldots \ldots \ldots$ \\
\hline
\end{tabular}

${ }^{a}$ Engineering units are shown in parentheses. 
TABLE II. - INPUT DATA SET FOR SPUROPT PROGRAM

\$ BLOCK A:

OPTIMIZATION DESIGN FOR LIFE OF SPUR GEARS

$\$$ BLOCK B:

2,3

$\$$ BLOCK C:

$0,5,7,1000$

$\$$ BLOCK D:

$\$$ BLOCK E:

$\$$ BLOCK F:

$5,1,+1.0$

$\$$ BLOCK G:

$30,60,36$.

$6,12,, 8$.

$0.2,0.4,0.25$

$\$$ BLOCK H:

1,3

1,4

2,5

3,6

3,7

$\$$ BLOCK I:

10

$\$$ BLOCK J:

$9,10,1$

$0,, 0,60000,0$

$11,11,1$

$0 ., 0,1 . \mathrm{E} 15,0$

$12,12,1$

$-1 . E+10,0,0,0$

$13,13,1$

$0 ., 0,275,0$

$14,14,1$

$1 ., 0,10,0$

$15,15,1$

$1 ., 0,3,0$

$16,17,1$

$1 ., 0,4.5,0$

$18,18,1$

$3.5,0,5 ., 0$

$19,20,1$

$0.044,0,0.056,0$

$21,21,1$

$0 ., 0,1 . E 15,0$

$\$$ BLOCK R:

END

$36 ., 36 ., 8,0.25,0.25,20$.

$386.3,5000$.

$0.000733,0.000733,30000000,30000000,0.3,0.3,16 ., 16$.

$0.001,20 ., 20 ., 2,2$.

$620,1,1 ., 1 ., 1.25$

$0.00013,0.0000018,7100,120$. 
TABLE III. - SPUR GEAR LIFE-OPTIMIZATION RESULTS:

\section{ORIGINAL PROGRAM USING GEOFAC}

(a) SI units

\begin{tabular}{|c|c|c|c|}
\hline Parameters & Initial value & Bounds & Final value \\
\hline Number of teeth & 36 & 30 to 60 & 58.8 \\
\hline Module, mm & 3.18 & 3.18 to 2.12 & 2.15 \\
\hline Face width, mm & 6.14 & 5.1 to 10.2 & 7.1 \\
\hline Width-to-diameter ratio & 0.056 & 0.044 to 0.056 & ${ }^{8} 0.056$ \\
\hline Weight, kg & 0.51 & 0.45 to 2.01 & 0.70 \\
\hline Center distance, $\mathrm{mm}$ & 114 & 90 to 127 & ${ }^{\mathrm{a}} 127$ \\
\hline Dynamic load, $\mathrm{N}$ & 5075 & & 5293 \\
\hline Bending stress, $\mathrm{MPa}$ & 910 & $<1241$ & 0.004 \\
\hline Contact stress, $\mathrm{MPa}$ & 1006 & $<1310$ & 896 \\
\hline Fatigue life, Mrev & 666 & . & 1962 \\
\hline
\end{tabular}

(b) Engineering units

\begin{tabular}{|c|c|c|c|}
\hline Parameters & Initial value & Bounds & Final value \\
\hline Number of teeth & 36 & 30 to 60 & 58.8 \\
\hline Diametral pitch, in.$^{-1}$ & 8.0 & 8.0 to 12.0 & 11.8 \\
\hline Face width, in. & 0.25 & 0.2 to 0.4 & 0.28 \\
\hline Width-to-diameter ratio & 0.056 & 0.044 to 0.056 & ${ }^{\mathrm{a}} 0.056$ \\
\hline Weight, lb & 1.13 & 1.0 to 4.5 & 1.55 \\
\hline Center distance, in. & 4.5 & 3.5 to 5.0 & $\mathrm{a}_{5.0}$ \\
\hline Dynamic load, lb & 1141 & & 1190 \\
\hline Bending stress, ksi & 132 & $<180$ & 0.6 \\
\hline Contact stress, ksi & 146 & $<190$ & 130 \\
\hline Fatigue life, Mrev & 666 & & 1962 \\
\hline
\end{tabular}

${ }^{\text {a }}$ Parameter at constraint limit. 


\section{TABLE IV. - SPUR GEAR LIFE-OPTIMIZATION RESULTS}

\section{USING JFACTR}

(a) SI units with $1241 \mathrm{MPa}$ bending-stress limit

\begin{tabular}{|l|c|c|c|}
\hline \multicolumn{1}{|c|}{ Parameter } & Initial value & Bounds & Final value \\
\hline Number of teeth & 36 & 30 to 60 & ${ }^{\mathrm{a}} 60.0$ \\
Module, mm & 3.18 & 3.18 to 2.12 & ${ }^{\mathrm{a}} 2.12$ \\
Face width, mm & 6.14 & 5.1 to 10.2 & 7.1 \\
Width-to-diameter ratio & 0.056 & 0.044 to 0.056 & ${ }^{\mathrm{a}} 0.056$ \\
Weight, kg & 0.51 & 0.45 to 2.01 & 0.70 \\
Center distance, mm & 114 & 90 to 127 & ${ }^{\mathrm{a}} 127$ \\
Dynamic load, N & 5075 & ------ & $\mathbf{5 2 9 3}$ \\
Bending stress, MPa & 614 & $<1241$ & 758 \\
Contact stress, MPa & 1006 & $<1310$ & 896 \\
Fatigue life, Mrev & 666 & - & 1985 \\
\hline
\end{tabular}

(b) Engineering units with $180 \mathrm{ksi}$ bending-stress limit

\begin{tabular}{|c|c|c|c|}
\hline Parameter & Initial value & Bounds & Final value \\
\hline Number of teeth & 36 & 30 to 60 & ${ }^{a} 60.0$ \\
\hline Diametral pitch, in. ${ }^{-1}$ & 8.0 & 8.0 to 12.0 & $\mathbf{a}_{12.0}$ \\
\hline Face width, in. & 0.25 & 0.2 to 0.4 & 0.28 \\
\hline Width-to-diameter ratio & 0.056 & 0.044 to 0.056 & ${ }^{\mathrm{a}} 0.056$ \\
\hline Weight, lb & 1.13 & 1.0 to 4.5 & 1.55 \\
\hline Center distance, in. & 4.5 & 3.5 to 5.0 & ${ }^{a_{5}} .0$ \\
\hline Dynamic load, lb & 1141 & 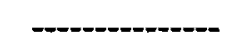 & 1190 \\
\hline Bending stress, ksi & 89 & $<180$ & 110 \\
\hline Contact stress, ksi & 146 & $<190$ & 130 \\
\hline Fatigue life, Mrev & 666 & $-\cdots$ & 1985 \\
\hline
\end{tabular}

${ }^{\text {a }}$ Parameter at constraint limit. 
TABLE V. - SPUR GEAR LIFE-OPTIMIZATION RESULTS

USING JFACTR AND LOWER BENDING-STRESS LIMIT

(a) SI units with $414 \mathrm{MPa}$ bending-stress limit

\begin{tabular}{|l|c|c|c|}
\hline \multicolumn{1}{|c|}{ Parameter } & Initial value & Bounds & Final value \\
\hline Number of teeth & 36 & 30 to 60 & ${ }^{\mathrm{a}} 30.0$ \\
Module, mm & 3.18 & 4.23 to 2.12 & $\mathrm{a}_{4.23}$ \\
Face width, mm & 6.14 & 5.1 to 10.2 & 7.1 \\
Width-to-diameter ratio & 0.056 & 0.044 to 0.056 & ${ }^{\mathrm{a}} 0.056$ \\
Weight, kg & 0.51 & 0.45 to 2.01 & 0.70 \\
Center distance, mm & 114 & 90 to 127 & ${ }^{\mathrm{a}} 127$ \\
Dynamic load, N & 4435 & - & 4831 \\
Bending stress, MPa & 538 & $<414$ & 414 \\
Contact stress, MPa & 1006 & $<1310$ & 903 \\
Fatigue life, Mrev & 666 & ------ & 1564 \\
\hline
\end{tabular}

(b) Engineering units with $60 \mathrm{ksi}$ bending-stress limit

\begin{tabular}{|l|c|c|r|}
\hline \multicolumn{1}{|c|}{ Parameter } & Initial value & Bounds & Final value \\
\hline Number of teeth & 36 & 30 to 60 & ${ }^{\mathrm{a}} 30.0$ \\
Diametral pitch, in. ${ }^{-1}$ & 8.0 & 6.0 to 12.0 & ${ }^{\mathrm{a}} 6.0$ \\
Face width, in. & 0.25 & 0.2 to 0.4 & 0.28 \\
Width-to-diameter ratio & 0.056 & 0.044 to 0.056 & ${ }^{\mathrm{a}} 0.056$ \\
Weight, lb & 1.13 & 1.0 to 4.5 & 1.55 \\
Center distance, in. & 4.5 & 3.5 to 5.0 & ${ }^{\mathrm{a}} 5.0$ \\
Dynamic load, lb & 997 & -------- & 1086 \\
Bending stress, ksi & 78 & $<60$ & 60 \\
Contact stress, ksi & 146 & $<190$ & 131 \\
Fatigue life, Mrev & 666 & ------- & 1564 \\
\hline
\end{tabular}

${ }^{\mathrm{a}}$ Parameter at constraint limit. 
TABLE VI. - SPUR GEAR LIFE-OPTIMIZATION RESULTS OF

TABLE V WITH ERROR CORRECTED

(a) SI units with $414 \mathrm{MPa}$ bending-stress limit

\begin{tabular}{|l|c|c|c|}
\hline \multicolumn{1}{|c|}{ Parameter } & Initial value & Bounds & Final value \\
\hline Number of teeth & 36 & 30 to 60 & 31.3 \\
Module, mm & 3.18 & 4.23 to 2.12 & 4.03 \\
Face width, mm & 6.14 & 5.1 to 10.2 & 7.1 \\
Width-to-diameter ratio & 0.056 & 0.044 to 0.056 & ${ }^{\mathrm{a}} 0.056$ \\
Weight, kg & 0.51 & 0.45 to 2.01 & 0.70 \\
Center distance, mm & 114 & 90 to 127 & 127 \\
Dynamic load, N & 4288 & $-\mathrm{a}_{12}$ & 4688 \\
Bending stress, MPa & 517 & $<414$ & $\mathrm{a}_{414}$ \\
Contact stress, MPa & 1006 & $<1310$ & 903 \\
Fatigue life, Mrev & 666 & - & 1592 \\
\hline
\end{tabular}

(b) Engineering units with 60 ksi bending-stress limit

\begin{tabular}{|l|c|c|r|}
\hline \multicolumn{1}{|c|}{ Parameter } & Initial value & Bounds & Final value \\
\hline Number of teeth & 36 & 30 to 60 & 31.3 \\
Diametral pitch, in. ${ }^{-1}$ & 8.0 & 6.0 to 12.0 & 6.3 \\
Face width, in. & 0.25 & 0.2 to 0.4 & 0.28 \\
Width-to-diameter ratio & 0.056 & 0.044 to 0.056 & $\mathrm{a}^{\mathrm{a}} 0.056$ \\
Weight, lb & 1.13 & 1.0 to 4.5 & 1.55 \\
Center distance, in. & 4.5 & 3.5 to 5.0 & $\mathrm{a}_{5.0}$ \\
Dynamic load, lb & 964 & ------- & 1054 \\
Bending stress, ksi & 75 & $<60$ & ${ }^{\mathrm{a}} 60$ \\
Contact stress, ksi & 146 & $<190$ & 131 \\
Fatigue life, Mrev & 666 & - & 1592 \\
\hline
\end{tabular}

${ }^{\text {a }}$ Parameter at constraint limit. 


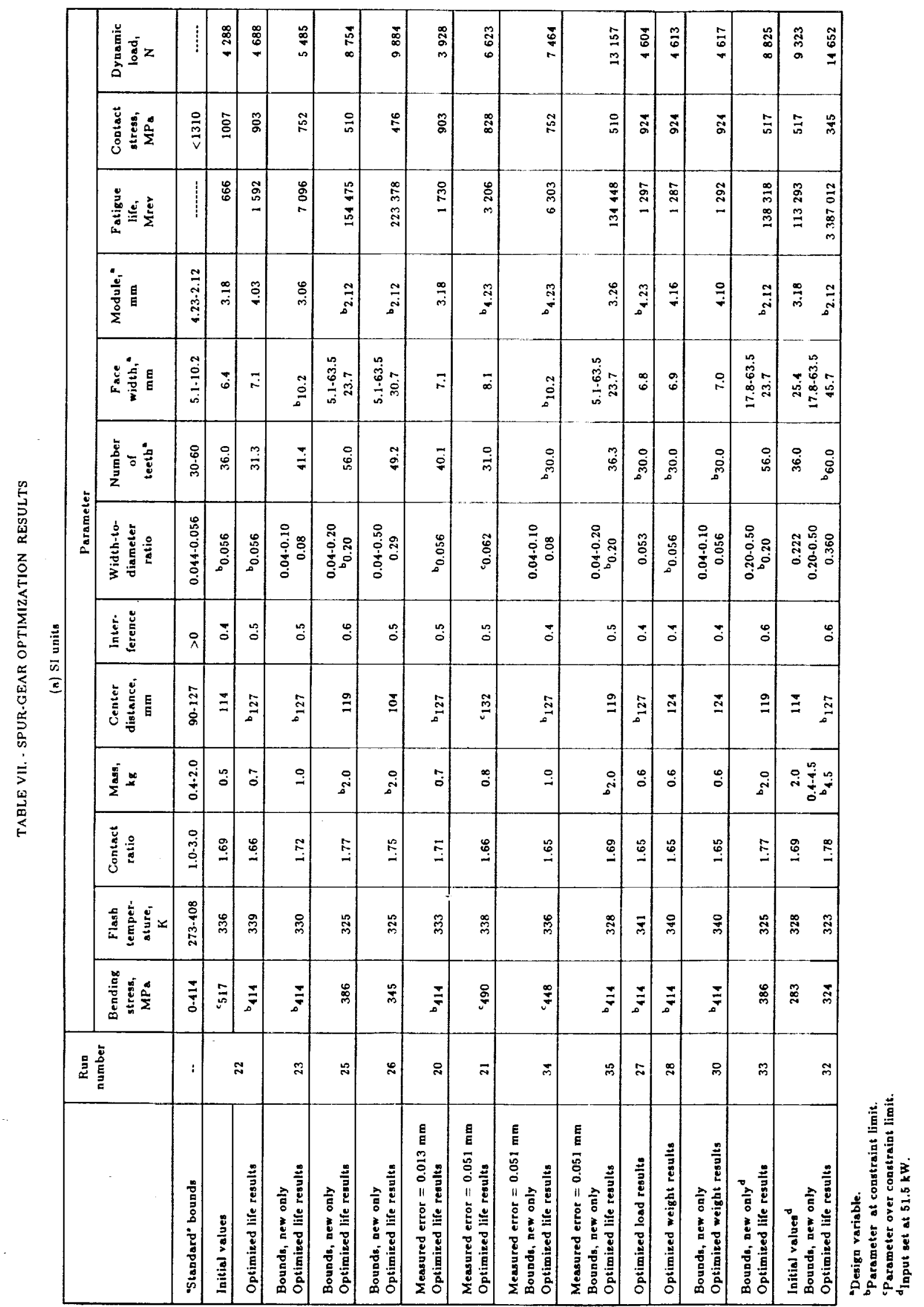




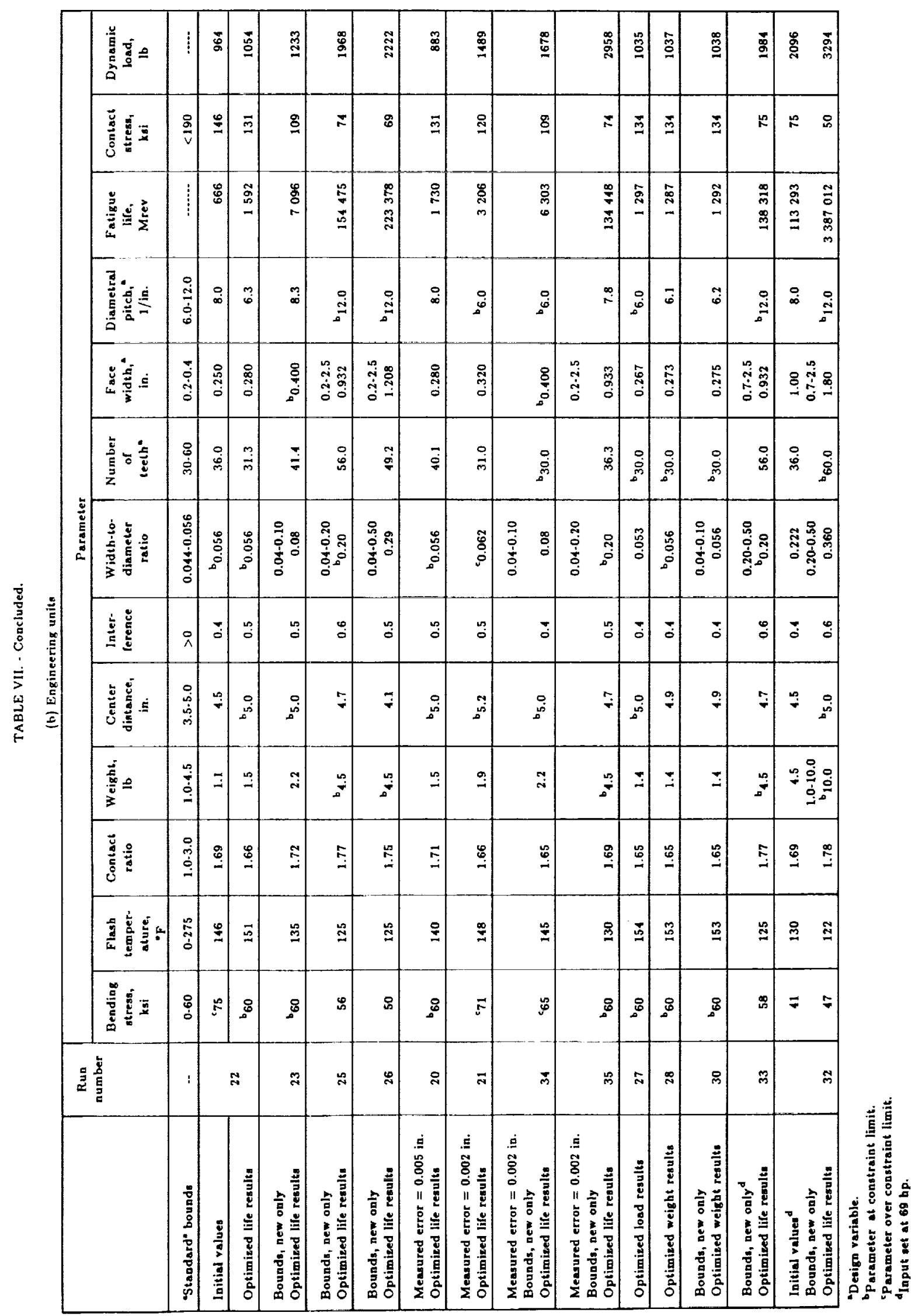




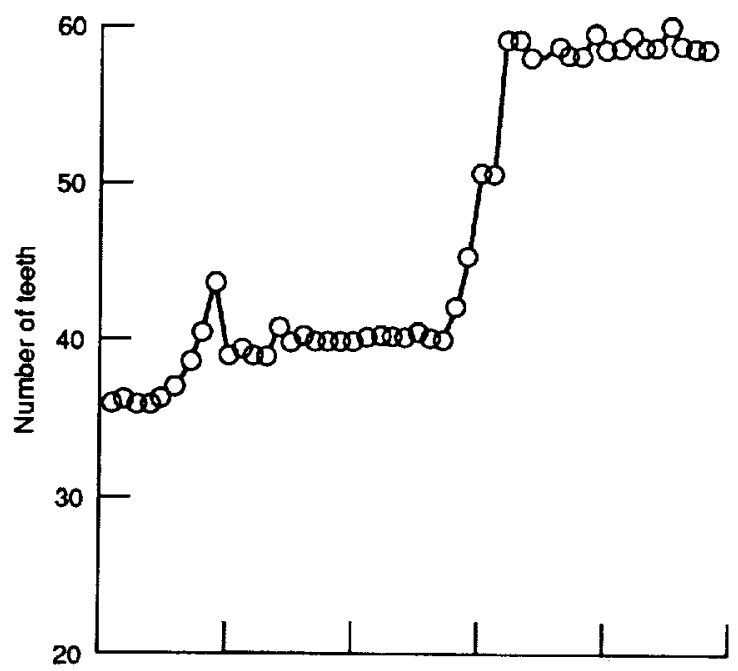

(a) Number of teeth.

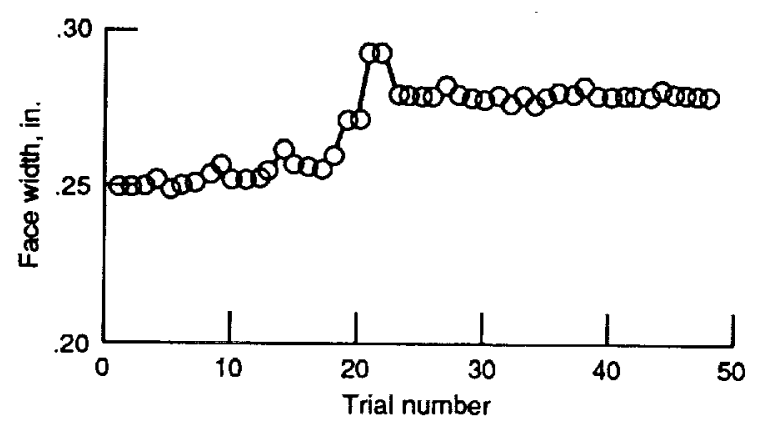

(c) Face width.

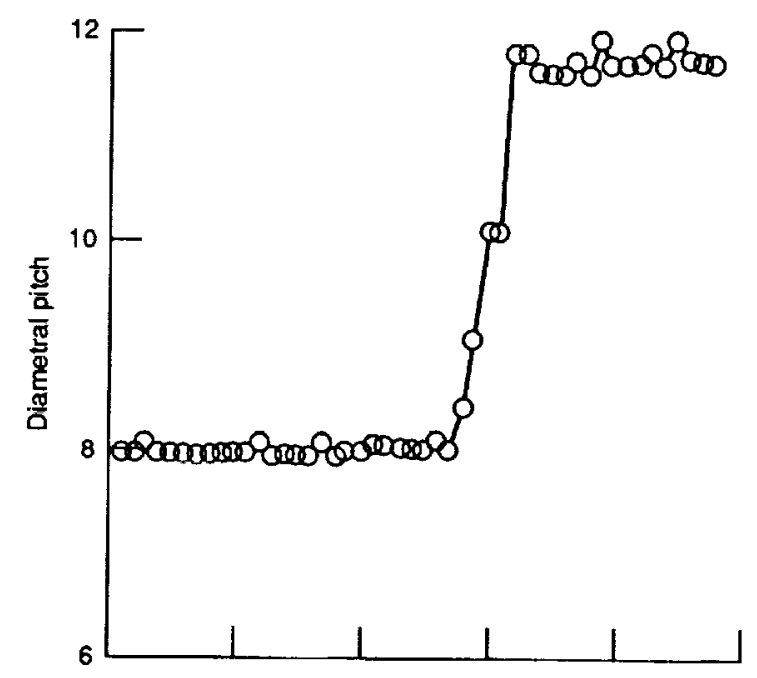

(b) Diametral pitch.

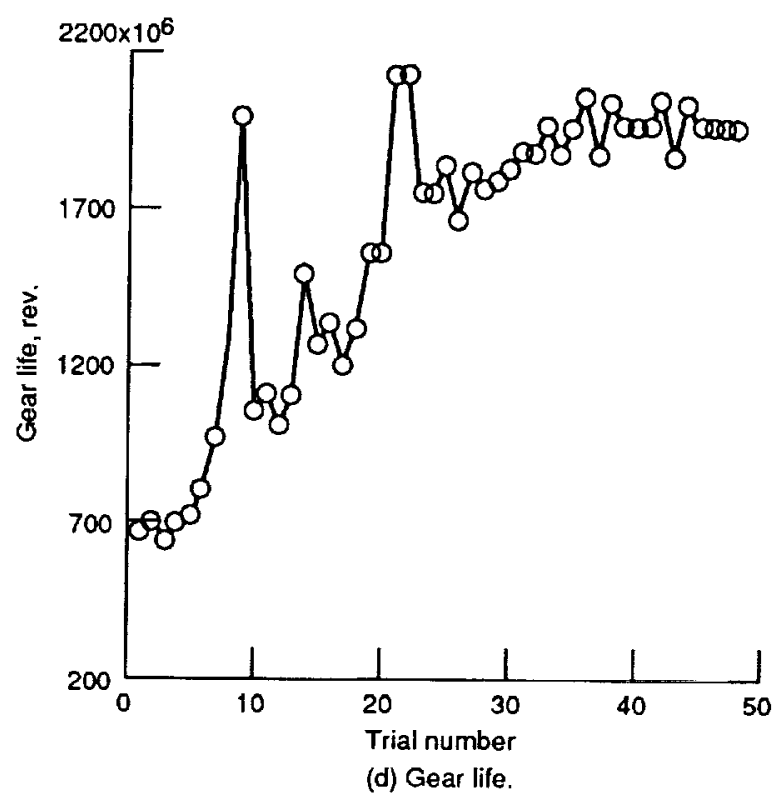

Figure 1.-Design variables and gear life as a function of optimizer trial number for input data from table I; allowable bending stress, $1241 \mathrm{MPa}$ (180000 psi). 


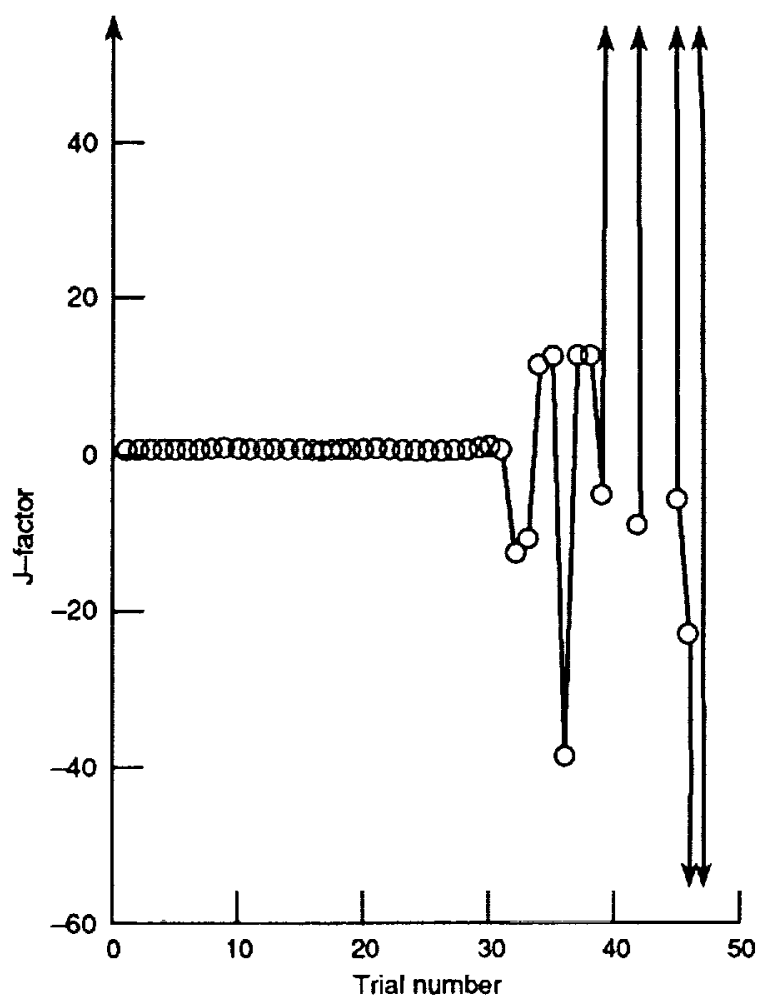

Figure 2.-J-factor as a function of optimizer trial number, using subroutine GEOFAC.

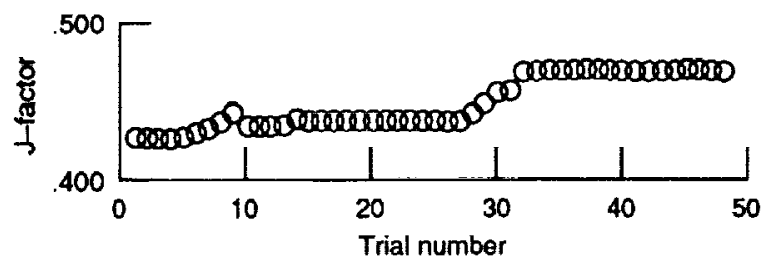

Figure 3.- J-factor as a function of optimizer trial number, using subroutine JFACTR. 




(a) Number of teeth.

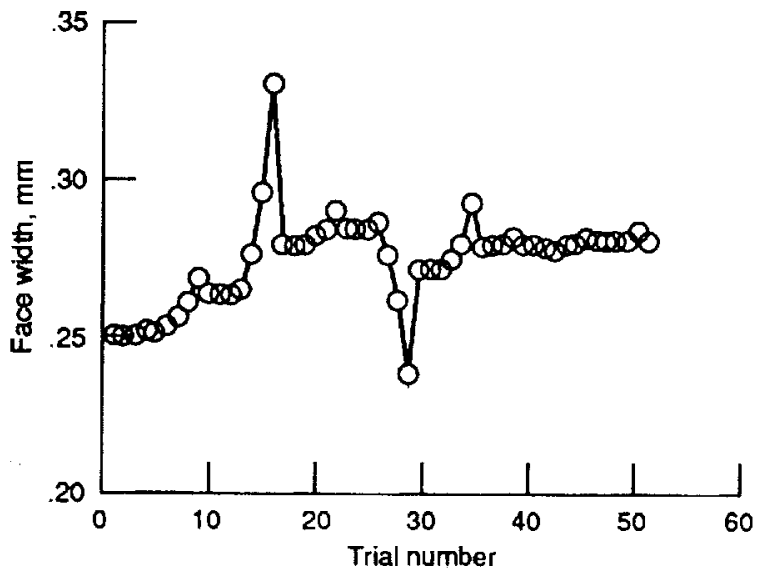

(c) Face width.

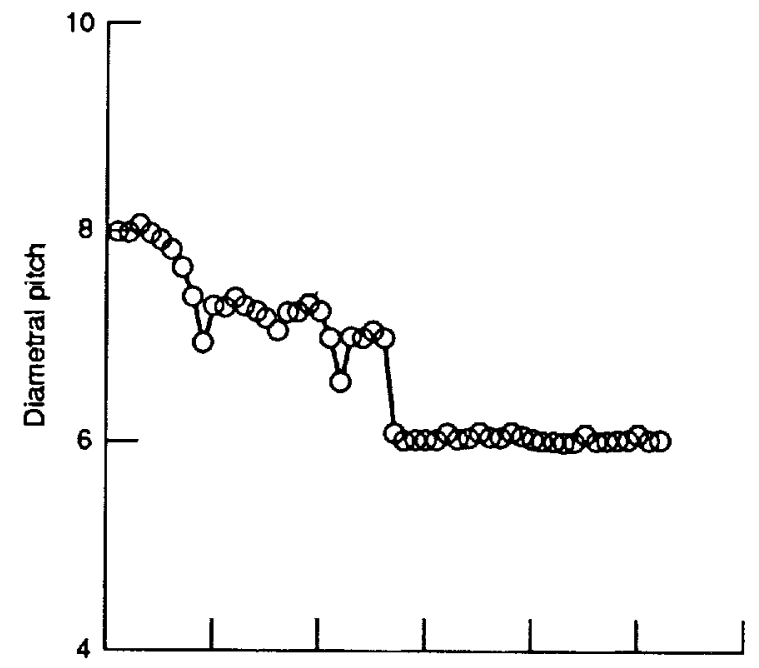

(b) Diametral pitch.

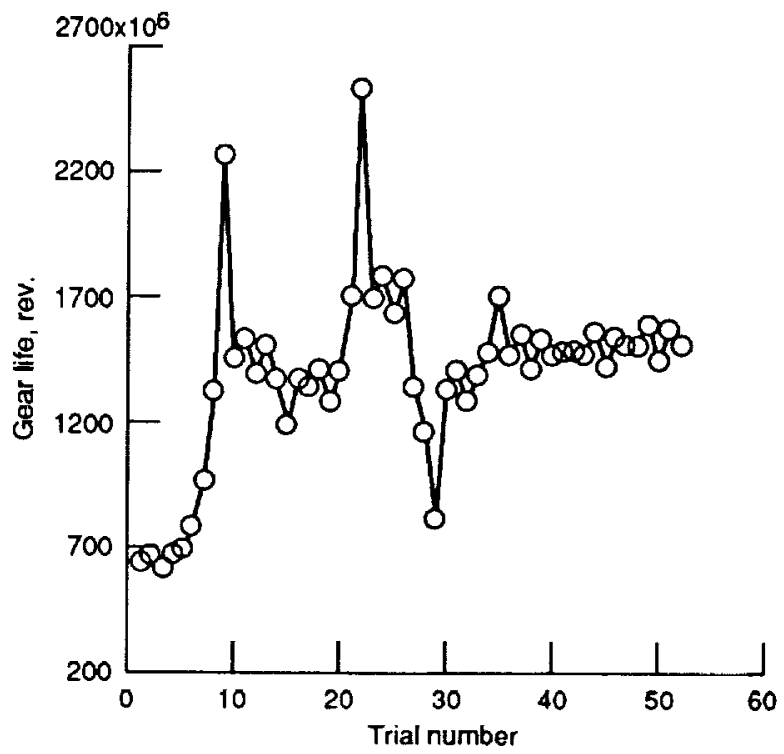

(d) Gear life.

Figure 4.-Design variables and gear life as a function of optimizer trial number for allowable bending stress of 414 $\mathrm{MPa}(60000 \mathrm{psi})$. 


\begin{tabular}{|c|c|c|c|}
\hline $\begin{array}{ll}\text { 1. Report No. } & \text { NASA TM - } 104394 \\
& \text { AVSCOM TR } 90-C-014\end{array}$ & 2. Government Accession No. & \multicolumn{2}{|c|}{ 3. Recipient's Catalog No. } \\
\hline \multirow{2}{*}{\multicolumn{2}{|c|}{$\begin{array}{l}\text { 4. Title and Subtitle } \\
\text { Spur Gear Optimization Using SPUROPT Computer Program }\end{array}$}} & \multicolumn{2}{|c|}{$\begin{array}{l}\text { 5. Report Dale } \\
\text { September } 1991\end{array}$} \\
\hline & & \multicolumn{2}{|c|}{ 6. Performing Organization Code } \\
\hline $\begin{array}{l}\text { 7. Author(s) } \\
\text { Harold H. Coe }\end{array}$ & & \multicolumn{2}{|c|}{$\begin{array}{l}\text { 8. Performing Organization Report No. } \\
\text { E-6210 }\end{array}$} \\
\hline \multirow{3}{*}{\multicolumn{2}{|c|}{$\begin{array}{l}\text { 9. Performing Organization Name and Address } \\
\text { NASA Lewis Research Center } \\
\text { Cleveland, Ohio } 44135-3191 \\
\text { and } \\
\text { Propulsion Directorate } \\
\text { U.S. Army Aviation Systems Command } \\
\text { Cleveland, Ohio } 44135-3191 \\
\end{array}$}} & \multicolumn{2}{|c|}{$\begin{array}{l}\text { 10. Work Unit No. } \\
\text { 505-63-51 } \\
\text { 1L162211 A47A }\end{array}$} \\
\hline & & \multicolumn{2}{|c|}{ 11. Contract or Grant No. } \\
\hline & & \multicolumn{2}{|c|}{$\begin{array}{l}\text { 13. Type of Report and Period Covered } \\
\text { Technical Memorandum }\end{array}$} \\
\hline \multicolumn{2}{|l|}{$\begin{array}{l}\text { 12. Sponsoring Agency Name and Address } \\
\text { National Aeronautics and Space Administ } \\
\text { Washington, D.C. } 20546-0001 \\
\text { and } \\
\text { U.S. Army Aviation Systems Command } \\
\text { St. Louis, Mo. } 63120-1798\end{array}$} & \multicolumn{2}{|c|}{ 14. Sponsoring Agency Code } \\
\hline \multicolumn{4}{|c|}{$\begin{array}{l}\text { 15. Supplementary Notes } \\
\text { Responsible person, Harold H. Coe, (216) 433-3971. }\end{array}$} \\
\hline \multicolumn{4}{|c|}{$\begin{array}{l}\text { 16. Abstract } \\
\text { SPUROPT, a computer program developed for optimizing spur gear designs, was updated by installing a new subroutine } \\
\text { that uses AGMA } 908-B 89 \text { standards to calculate the J-factor for determining tooth-bending stress. The updated } \\
\text { SPUROPT program was then used to optimize a spur gear set for maximum fatigue life, minimum dynamic load, or } \\
\text { minimum weight. All calculations were made with constraints on as many as } 13 \text { parameters by using three design } \\
\text { variables: the number of teeth, diametral pitch, and tooth-face width. Results depended largely on constraint values. } \\
\text { When the limiting bending stress was set at a high value, the optimal solution was the highest allowable number of teeth. } \\
\text { When the allowable bending stress was lowered, the optimal solution moved toward the fewest number of teeth permitted. } \\
\text { Final results were also affected by the amount of transmission error. A lower error permitted a higher number of teeth. }\end{array}$} \\
\hline $\begin{array}{l}\text { 17. Key Words (Suggested by Author(s)) } \\
\text { Optimization } \\
\text { Computer program } \\
\text { Gears } \\
\text { Design }\end{array}$ & 18. Distri & $\begin{array}{l}\text { - Unlimited } \\
\text { gory } 37\end{array}$ & \\
\hline
\end{tabular}

